\title{
Exploring the Role of Sexed Semen in Dairy Production Systems*
}

\author{
K. A. Weigel \\ Department of Dairy Science, University of Wisconsin, Madison 53706
}

\begin{abstract}
The availability of sexed semen in dairy cattle has been eagerly anticipated for many years, and recent developments in fluorescence activated cell sorting have brought this technology to the brink of commercial application. Two limitations still exist, namely sorting speed (hence, availability and price) and in vivo conception rates. Presently, about 150 to 200 straws of Xbearing sperm can be sorted per machine per day, and this comprises less that $0.5 \%$ of the daily domestic dairy semen requirement. Furthermore, conception rates in field trials involving virgin heifers have typically ranged from 35 to $40 \%$ with sexed semen, as compared with 55 to $60 \%$ for unsexed semen, and this limits the willingness of producers to pay a premium price for the product. The focus of this paper is to discuss 3 potential breeding schemes that can lead to widespread usage of sexed semen today, in spite of its aforementioned limitations. The first strategy, earlier (than normal) breeding of virgin heifers with sexed semen, followed by the use of unsexed semen for repeat services, would provide 62 to $66 \%$ female offspring at first calving with no detrimental effects on average age at calving or dystocia. Semen cost per heifer calf would increase by $\$ 47$ to $56, \$ 123$ to 137 , or $\$ 199$ to 217 , depending on conception rate, for sexed semen priced at $\$ 50, \$ 100$, or $\$ 150$ per unit, respectively. The second strategy, in vitro embryo production using known donors with dairy heifers as recipients, could provide extra heifer calves at an added cost of $\$ 81$ to 118 or $\$ 212$ to 286 for female embryos costing $\$ 50$ or $\$ 100$, respectively. The third strategy, in vitro embryo production with anonymous donors and beef recipients, could increase net calf value per recipient by $\$ 52$ to 97 (single transfers) or $\$ 171$ to 240 (double transfers) for embryos costing $\$ 25$ each and by $\$ 11$ to 59 (single transfers) or $\$ 95$ to 161 (double transfers) for embryos that cost $\$ 50$. Thus, strategies exist for near-term application of sexed semen within
\end{abstract}

Received July 8, 2003.

Accepted August 27, 2003.

E-mail: weigel@calshp.cals.wisc.edu.

*Presented at a symposium titled "Physiology_Gamete Physiology" of the ADSA-ASAS Joint Annual Meeting, June 2003, Phoenix. AZ. the routine management of commercial dairy farms. Early adopters of this technology will capture economic benefits associated with extra replacement heifers, as well as enhanced biosecurity via the ability to expand rapidly from within a closed herd.

(Key words: sexed semen, replacement heifer, embryo transfer, in vitro production)

Abbreviation key: ET = embryo transfer, IVP = in vitro embryo production, MAS = marker-assisted selection, MOET $=$ multiple ovulation and embryo transfer.

\section{INTRODUCTION TO SPERM SEXING TECHNOLOGY}

Separation of bovine semen into fractions enriched for X-bearing sperm has been discussed for decades, and scientists have predicted a far-reaching impact of this technology. The technology would enhance producers' ability to obtain inexpensive replacement heifers; this would fuel "biosecure" herd expansions and mitigate some of the effects of high involuntary culling rates and poor reproductive efficiency. Altering the sex ratio could also increase the effectiveness of AI progeny testing programs, as well as the efficiency of multiple ovulation and embryo transfer (MOET) and in vitro embryo production (IVP) programs.

Various approaches for separating X- and Y-bearing sperm have been examined. Immunological sexing, i.e., killing the Y-bearing sperm, has been attempted in several studies (e.g., Bradley, 1989; Blecher et al., 1999), and one can imagine the creation of transgenic bulls that are able to produce only X-bearing sperm. However, the only proven method for separating male- and female-bearing sperm is the fluorescence activated cell sorting approach of Johnson et al. (1987a, 1987b, 1989, and 1999). Also known as the "Beltsville Sperm Sexing Technology," this method was subsequently licensed to XY, Inc. (www.xyinc.com) for commercial development. Because the bovine $\mathrm{X}$ chromosome contains 3.8\% more DNA than its Y counterpart, sperm can be treated with DNA-specific fluorescent dye and subsequently sorted using high-throughput flow cytometry. However, many sperm are damaged, and a large proportion (e.g., 70\%) remain unsorted. This procedure, although remarkably fast by "laboratory standards" is remarkably slow by "commercial standards." As noted by Johnson et al. (2000), speed of the sorting process has improved nearly 
50 -fold in the past decade, and roughly 18 million sperm can now be sorted per hour. At this rate, up to 215 straws of X-bearing sperm (with 2 million sperm/straw) could be produced per machine in a 24 -h period, but US dairy producers currently use approximately 43,825 units of dairy semen each day. Another 50 -fold gain in speed is unlikely, given concurrent concerns about sperm damage and compromised conception rates.

The objective of this paper is not to forecast improvements in the efficiency of sperm sorting that will subsequently allow sexed semen to be used in conventional breeding programs. Rather, the objective is to develop and evaluate several "alternative" breeding strategies in which sexed semen technology can be implemented today, regardless of the aforementioned limitations in sorting speed and conception rate. In other words, this study seeks to explore commercial applications that can capitalize on the benefits of sexed semen, while respecting the current limits of the technology. The focus of this study is further limited to applications that will result in widespread use of sexed semen within the routine management system of commercial dairy farms, rather than niche applications that will be limited to a few selected pedigree breeders.

\section{REVIEW OF ITS IMPACT ON GENETIC PROGRESS AND HERD MANAGEMENT}

Predictions in the scientific literature regarding the impact of sexed semen on genetic progress vary widely, as do projections of its impact on the profitability of dairy farmers. Van Vleck and Everett (1976) estimated that producers could afford to pay as much as $\$ 15.67$ per unit for sexed semen, assuming an average cost of $\$ 6.00$ for unsexed AI semen at that time. Later, Van Vleck (1981) revised this estimate up to $\$ 19.00$ per unit of sexed semen and concluded that the rate of genetic progress in dairy cattle could increase by $15 \%$ if this product were widely available. However, later studies have predicted a much more modest improvement in genetic progress. Baker et al. (1990) suggested that the ability to alter the sex ratio of the offspring of elite sires and cows would have a very minor impact on the rate of genetic progress. However, they (Baker et al., 1990) predicted that sexed semen would have a major effect on the efficiency of farming systems, particularly in situations where male dairy calves have minimal (or perhaps negative) economic value. Montaldo et al. (1998) estimated that the rate of genetic gain in MOET nucleus schemes would increase by only 0.4 to $1.4 \%$ with sexed semen, although the availability of sexed semen would greatly enhance the efficiency of these programs by allowing the same rate of genetic progress with fewer transfers.
An additional advantage may be captured if the technologies of MOET, sexed semen, and marker-assisted selection (MAS) are combined. A limiting factor with respect to the application of MAS is the difficulty in producing more than 3 or 4 same-sex full-siblings using conventional embryo transfer (ET). For example, even if a particular elite sire or dam is heterozygous for a QTL of interest, one can easily end up with no male calves that possess the desired genotype, pass all necessary health tests, and produce viable semen. If the sire or dam is heterozygous for 2 or 3 different QTL, the chance of obtaining a healthy calf of the appropriate sex that has inherited all of the desired QTL alleles is negligible. Because the use of sexed semen would (nearly) double the size of each same-sex full-sib family, opportunities for MAS would be greatly enhanced.

The impact of sexed semen on herd management will likely be much greater than the corresponding impact on genetic progress. For example, using X-bearing sperm to mate virgin dairy heifers would substantially decrease the incidence of calving problems (dystocia), because female calves are smaller than males. In addition, the average lactation length of high-producing dairy cows could be extended to 18,20 , or even $24 \mathrm{mo}$, because these cows could easily provide their own replacements while averaging fewer than 2 calves per lifetime. Some authors, such as Van Vleck (1999) and Hohenboken (1999), have suggested that dairy producers could breed the top 50\% of their cows, genetically speaking, using X-bearing dairy semen to produce replacement heifers. Meanwhile, the bottom 50\% of their cows could be mated using Y-bearing beef semen to produce crossbred market steers. However, this strategy is unlikely to be adopted in practice for 2 reasons. First, the conception rates achieved with sexed semen in high-producing lactating cows will be unacceptably low, given the price of the product. Second, the increase in value of crossbred bull calves relative to their purebred counterparts will be virtually negligible relative to the potential value of the milk from their dams. Therefore, if a producer doesn't want heifer calves from a group of genetically inferior cows, a more sensible strategy would be to avoid breeding these cows altogether and instead extend their (terminal) lactations using bST.

Hohenboken (1999) discussed the potential benefits of using sexed semen in a crossbreeding scheme, albeit in beef cattle. In a terminal 3 -breed cross, $20 \%$ of the population consists of purebred cows to produce purebred females, $24 \%$ consists of purebred cows to produce crossbred females, and 56\% consists of crossbred cows to produce terminal market steers. With sexed semen, these proportions could change to 11,13 , and $76 \%$, respectively, thereby increasing the number of market 
WEIGEL

Table 1. Summary of field trials conducted by XY, Inc., using sexed semen in Holstein heifers in Colorado.

\begin{tabular}{lllll}
\hline & & \multicolumn{2}{c}{ Pregnancy rate } \\
\cline { 4 - 5 } Sperm type & Sperm unit & Placement & $30-33 \mathrm{~d}$ & $64-67 \mathrm{~d}$ \\
\hline Sexed & 1.5 million & Uterine body & $57 \%(67 / 117)$ & $55 \%(64 / 117)$ \\
Sexed & 1.5 million & Uterine horn & $48 \%(27 / 56)$ & $41 \%(23 / 56)$ \\
Sexed & 3 million & Uterine body & $51 \%(58 / 114)$ & $46 \%(53 / 114)$ \\
Sexed & 3 million & Uterine horn & $55 \%(31 / 56)$ & $48 \%(27 / 56)$ \\
Unsexed & 20 million & Uterine body & $74 \%(87 / 118)$ & $69 \%(82 / 118)$ \\
\hline
\end{tabular}

steers produced each year and, in turn, enhancing the profitability of the beef operation. Although crossbreeding is not popular among dairy producers today, added benefits may be attainable with sexed semen. For example, one could produce first cross $\left(\mathrm{F}_{1}\right)$ female Holstein $\times$ Jersey embryos (e.g., via IVP with anonymous donors) and implant these into Holstein heifers. In subsequent generations, additional $\mathrm{F}_{1}$ Holstein $\times$ Jersey embryos could be transferred into the existing $\mathrm{F}_{1}$ Holstein $\times$ Jersey cows and heifers, thereby creating a continuous, terminal dairy crossbreeding scheme that would maximize heterosis while improving milk composition and reducing dystocia.

An additional, often overlooked, benefit of sexed semen is biosecurity. Commercial dairy herds are expanding rapidly in many states, as financial pressure leads producers to seek economies of scale. However, rapid expansion from within a closed herd is impossible without sexed semen or embryos. Therefore, most producers purchase cows and heifers from auctions, cattle dealers, or other farmers. When these animals arrive, the farm may be exposed to many new pathogens (e.g., leptospirosis, paratuberculosis). The rate of involuntary culling subsequently increases due to greater frequency of disease, inability of older cows to adapt to facilities, and poor genetic potential among purchased animals and their offspring. As a result, the producer needs more replacements, and the cycle continues. The availability of sexed semen would allow producers to expand from within a closed herd and avoid many of the aforementioned problems. Likewise, a cow-calf beef operation (on which the frequency of common "dairy" diseases may be low) could derive additional income by "renting" recipients to a neighboring dairy farmer who wishes to expand in a biosecure manner.

\section{RESULTS OF IN VIVO FIELD TRIALS}

Numerous field trials with sexed bovine semen have been conducted within the past $5 \mathrm{yr}$ in the United States, and most have used virgin heifers as mates due to concerns about conception rate. Results from several trials conducted by XY, Inc. in Colorado (Seidel et al., 1999) are summarized in Table 1. Mean pregnancy rates with unsexed control semen were $74 \%$ at examinations 30 to $33 \mathrm{~d}$ after insemination and $69 \%$ at reexaminations 64 to $67 \mathrm{~d}$ after insemination. Pregnancy rates with sexed semen at 30 to $33 \mathrm{~d}$ after insemination ranged from 48 to $55 \%$, but the effects of sperm concentration ( 1.5 vs. 3 million per straw) and semen placement (uterine horn vs. uterine body) were minimal. Pregnancy loss between 30 and $33 \mathrm{~d}$ and 64 and $67 \mathrm{~d}$ after insemination with sexed semen ranged from 2 to $7 \%$, similar to the rate observed with unsexed semen.

Results from 3 additional field trials in New York, California, and in both California and Texas are shown in Table 2 (Seidel and Shenk, 2002). Conception rates with unsexed control semen were 62,61 , and $43 \%$, respectively, in these studies. In the New York study, sexed semen at concentrations of 1.5 million and 6 million sperm per unit gave conception rates of 43 and $41 \%$, respectively. In the other 2 studies, low concentration ( 2 million sperm per unit) unsexed semen resulted in concentration rates of 49 and $46 \%$, respectively, while low-concentration, centrifuged unsexed semen resulted in conception rates of 46 and 38\%, respectively. Mean conception rate with sexed semen in both studies was $31 \%$.

Results of an additional field trial in Wisconsin, in which conception rates with sexed semen were compared in herds with below average, average, or above average reproductive efficiency, are shown in Table 3 (Seidel and Shenk, 2002). Mean conception rate with unsexed semen was $58 \%$ across all herds, while conception rates with sexed semen were 21,37 , and $35 \%$ in below average, average, and above average herds, respectively.

Based on these results, it is clear that conception rates are compromised by semen sorting, at least at present, and strategies for in vivo commercial application should focus on approaches that provide cost-effective use of sexed semen without significantly extending average age at first calving.

\section{IN VITRO EMBRYO PRODUCTION WITH SEXED SEMEN}

Because sorting speed (and, hence semen availability) is a major concern, one would hypothesize that 
Table 2. Summary of field trials in Holstein and Jersey heifers by AI technicians and do-it-yourself (DIY) inseminators in commercial dairy herds.

\begin{tabular}{lllrl}
\hline Location, date & Mates & Semen type & Sperm/unit & $\begin{array}{l}\text { Conception } \\
\text { rate }\end{array}$ \\
\hline New York & Holsteins $(\mathrm{N}=797)$ & Sexed & 1.5 million & $43 \%$ \\
Jul. '00-May'01 & & Sexed & 6 million & $41 \%$ \\
DIY inseminators & & Unsexed & 20 million & $62 \%$ \\
California & Jerseys $(\mathrm{N}=637)$ & Sexed & 2 million & $31 \%$ \\
Jan. '01-Sep. '01 & Unsexed, centrifuged & & 2 million & $46 \%$ \\
AI technicians & & Unsexed & 2 million & $49 \%$ \\
& & Unsexed & 20 million & $61 \%$ \\
California, Texas & Holsteins $(\mathrm{N}=513)$ & Sexed & 2 million & $31 \%$ \\
Apr. '01-Aug. '01 & Unsexed, centrifuged & & 2 million & $38 \%$ \\
DIY Inseminators & & Unsexed & 2 million & $46 \%$ \\
& & Unsexed & 20 million & $43 \%$ \\
\hline
\end{tabular}

breeding programs based on IVP may be commercially applicable before corresponding in vivo applications. Lu et al. (1999) reported that a similar percentage of ova seem to be fertilized when using sexed or unsexed bovine sperm, but the rate of blastocyst production with sexed semen appears to be only about $70 \%$ of that obtained with unsexed semen. In addition, blastocyst production may be delayed slightly (about $1 / 2$ day) in some cases. Nonetheless, their (Lu et al., 1999) field trial involving 106 double (i.e., twin) transfers of IVP embryos produced with Y-bearing sperm led to 41 live calves, of which $90 \%$ were male.

Wilson et al. (2003) reported the results of an IVP project with sexed semen on 7 commercial dairies in Wisconsin. Each month, farmers identified "genetically useful" cull cows from which they desired additional offspring ( $\mathrm{N}=88$ donors). Ovaries were retrieved at slaughter, and the recovered ova were joined with sexed sperm from 3 young Holstein sires. Fresh embryos were transferred back into recipient cows and heifers on the same farms. An average of 3.8 transferable embryos were produced per donor cow, although only 2.7 were actually transferred due to large variation among donors and corresponding shortages in recipients. Mean pregnancy rates for IVP embryos were 18\% in recipient cows (timed breeding) and $40 \%$ in recipient heifers (standing heats). Mean pregnancy rate from timed AI in control cows was $36 \%$, so it appears that transferring IVP embryos into high-producing cows will not lead to acceptable pregnancy rates. Conversely, transferring IVP embryos into virgin heifers leads to the risk of severe calving difficulty in (rather rare) cases of extremely large IVP calves.

Amman (1999) observed that the ultimate use of the sexed semen is a critical consideration before sorting begins. For example, roughly 2 million sperm per unit are required to inseminate a dairy heifer in vivo, while $<100,000$ sperm are needed to fertilize 100 ova in an IVP program. Therefore, sperm could be sorted more slowly (perhaps with less damage) for use in IVP, and the semen could be packaged in straws containing 100,000 or fewer sperm per dose.

When producing sexed semen for use in an IVP program, one must decide whether to sort fresh semen (as is typically the case) or thawed, frozen semen. The latter approach has 2 limitations. First, relatively few X-bearing sperm can be isolated from a straw of thawed semen, after accounting for the killed, damaged, unsorted, and Y-bearing fractions. Second, thawed semen appears to have poorer staining qualities, and this may complicate efforts to separate X- and Y-bearing sperm. However, Lu et al. (1999) noted that sex ratios greater than 80:20 (in favor of either sex) could be obtained in an IVP program when thawed, frozen semen was subsequently stained and sorted using flow cytometry. Because so few sperm are needed for IVP applications, thawed semen may also offer some advantages. Semen availability would be greatly improved, in the sense that IVP

Table 3. Summary of a field trial conducted from February to June 2001 in Wisconsin involving 816 Holstein heifers. AI technicians, and herds with below average, average, or above average reproductive efficiency.

\begin{tabular}{llll}
\hline Semen type & Sperm/unit & $\begin{array}{l}\text { Herd reproduction } \\
\text { level }\end{array}$ & $\begin{array}{l}\text { Conception } \\
\text { rate }\end{array}$ \\
\hline Sexed & 2 million & Below average & $21 \%$ \\
Sexed & 2 million & Average & $37 \%$ \\
Sexed & 2 million & Above average & $35 \%$ \\
Unsexed & 20 million & All & $58 \%$ \\
\hline
\end{tabular}


programs would gain access to sexed semen from a much wider variety of bulls. Furthermore, the need to sort an entire ejaculate of an elite dairy sire might be eliminated, thereby saving a significant "opportunity cost" (associated with killing or discarding a large proportion of this valuable semen).

While considering "custom sorting" applications, we should recognize that an 85:15 or 90:10 sex ratio may not be desirable in all applications. For example, in MOET nucleus schemes both male and female offspring of elite donor dams are needed. In this case, one may choose to alter sorting conditions such that a sex ratio of 70:30 or 65:35 is obtained. Furthermore, one may desire different sex ratios in different types of breedings within a MOET nucleus program. For example, the first flush of an elite yearling heifer might be used to produce male calves, such that the AI stud could begin rearing these calves to semen-producing age quickly, relative to the time at which their dams will receive their first genetic information. The second and third flushes could subsequently produce female calves that would be raised as potential replacement heifers in the next generation of the MOET herd. One concern of Amman (1999) was that the potential market for sexed semen to be used in IVP applications is quite small, such that this market might be satisfied by a single sorting machine. In that sense, creation of female IVP embryos might be considered a "niche" application. However, if it is possible to produce large quantities of IVP dairy embryos (e.g., using ovaries obtained from an abattoir), and if the demand for these embryos among beef and/ or dairy producers is large, then sexing even a small amount of semen could have a potentially large impact on a dairy production system.

\section{ISSUES REGARDING COMMERCIAL IMPLEMENTATION}

Are we finally on the verge of commercial application of sexed semen technology? By some accounts, we've been a bit premature in declaring this technology "commercially ready" in the past. For example, consider the "news" item reported in the October 1978 issue of Livestock Farming (page 50):

"A company (name withheld) is offering a semen sexing service to cattle breeders, i.e., separation of semen into $X$ and $Y$ bearing fractions. It can be used on fresh or thawed semen. The cost of separation is \$15-20 per ampoule, depending on the size of the order."

Had this semen sexing service materialized, numerous producers would have leapt at the chance to obtain sexed semen at such a modest price. However, this announcement was at least a quarter century ahead of its time, and current efforts to commercialize this tech- nology should be cognizant of farmers' concerns about previous failures to deliver the product. Young et al. (1988) noted that the vast majority of dairy producers express keen interest in acquiring sexed semen, so one can hypothesize a high rate of adoption very quickly after this product becomes available. However, they (Young et al., 1988) also noted that the rate of adoption for many simple, inexpensive technologies that are widely known to enhance profitability, such as AI or milk recording, is far less than $100 \%$.

What are the criteria for "successful implementation" of a new technology? The present paper relies on the following (perhaps restrictive) definition: a technology has been successfully implemented when it becomes integrated into the routine management of commercial dairy operations. By this definition, one can easily identify several "successes," including AI, recombinant bST, total mixed rations, timed breeding programs and evaporative cooling systems. By the same token, one can list several "failures," including ET and IVP (with aspiration of ova from live donors). The use of these technologies, up to this point, has been limited to a few highly marketable animals owned by a very small number of pedigree breeders.

Like many agricultural technologies, the ultimate beneficiary of sexed semen will be the consumer, who will continue to enjoy high-quality dairy products at affordable prices. Among agribusinesses and producers, early adopters of the technology will derive the greatest benefits, and widespread availability of X-bearing sperm and, hence, inexpensive replacement heifers, could eventually mitigate some of these benefits. Cost of the technology, including purchase of the sorting machine(s), maintenance costs, licensing fees, royalties, and additional labor, is a major concern. One company, Cogent (www.cogentuk.com), has begun offering sexed semen commercially. Cogent operates roughly a dozen sorting machines and sells X-bearing semen to dairy producers in Great Britain and several other countries. However, this company is currently not licensed to sell sexed semen in the United States. Results of this initial "commercialization experience" are difficult to quantify due to the lack of any scientific data or published results.

Given the limitations of sexed semen, primarily conception rate and sorting speed (hence, low availability and high price), we have 3 options. First, we can dwell on these limitations and wait for them to go away, if ever. In other words, we can let reproductive biologists "tweak" the current method (or develop a new method) that will provide conception rates comparable with unsexed semen and will produce thousands of units of sexed semen each day. Second, we can ignore these limitations and use sexed semen in the same way we 
Table 4. Example of cost per heifer calf using sexed semen on every service (initial and repeat) for 1000 dairy heifers, according to conception rate and cost per unit of sexed semen. Calculations assume that unsexed semen costs $\$ 15$ per unit and that sexed semen results in $85 \%$ heifer calves.

\begin{tabular}{|c|c|c|c|c|c|c|c|c|c|}
\hline \multirow{2}{*}{$\begin{array}{l}\text { Semen } \\
\text { type }\end{array}$} & \multirow{2}{*}{$\begin{array}{l}\text { Conception } \\
\text { rate }\end{array}$} & \multicolumn{3}{|c|}{ No. pregnant at service } & \multirow{2}{*}{$\begin{array}{l}\text { Units of } \\
\text { semen }\end{array}$} & \multirow{2}{*}{$\begin{array}{l}\text { Heifer } \\
\text { calves }\end{array}$} & \multicolumn{3}{|c|}{ Cost per heifer calf } \\
\hline & & 1 & 3 & 5 & & & $\$ 50$ Semen & $\$ 100$ Semen & $\$ 150$ Semen \\
\hline Unsexed & $60 \%$ & 600 & 936 & 990 & 1666 & 500 & $\$ 50$ & $\$ 50$ & $\$ 50$ \\
\hline Sexed & $40 \%$ & 400 & 784 & 922 & 2485 & 845 & $\$ 147$ & $\$ 294$ & $\$ 441$ \\
\hline Sexed & $35 \%$ & 350 & 725 & 884 & 2819 & 839 & $\$ 168$ & $\$ 336$ & $\$ 504$ \\
\hline
\end{tabular}

have used unsexed semen for decades. In other words, we can use this expensive semen carelessly, without making any substantial modifications to our breeding programs (we'll fail, of course, and then we'll conclude that the technology doesn't work). Third, we can recognize these limitations and develop new breeding strategies that are "tailor-made" for sexed semen. In other words, we can formulate programs that utilize sexed semen in an efficient, cost effective manner, even if the product is expensive and conception rates are compromised. Three such programs are described in the next section, but first let us review the results that we would expect by using sexed semen in a more "conventional" manner (i.e., by using sexed semen "across the board" on dairy heifers).

Table 4 illustrates the expected cost per heifer calf when sexed semen is used for all inseminations in virgin dairy heifers (i.e., first service and all repeat services), according to semen price and conception rate. Assuming 1000 heifers and a conception rate of $60 \%$ with unsexed semen, the number of pregnant heifers would be 600 after first service, 936 after third service, and 990 after fifth service. A total of 1666 units of semen would be used, and 500 heifer calves would be produced. Semen cost per heifer calf would be $\$ 50$, assuming a per unit price of $\$ 15$ for unsexed semen. Three different conception rates were considered for sexed semen: 45,40 , or $35 \%$, and the assumed sex ratio was 85:15 in favor of females. Given these conception rates, the number of pregnant heifers after 3 services would be 834, 784, or 725 , respectively, and the corresponding number of pregnancies after 5 services would be 950,922 , or 884 , respectively. The total number of units of sexed semen required would range from 2217 to 2819 , depending on conception rate. At a conception rate of $45 \%, 848$ heifer calves would be produced, and the additional cost per heifer calf (relative to controls) would be $\$ 81, \$ 211$, or $\$ 342$ for sexed semen costing $\$ 50, \$ 100$, or $\$ 150$ per unit, respectively. Likewise, a conception rate of $40 \%$ would lead to 845 heifer calves, and the additional cost per calf would be $\$ 97, \$ 244$, or $\$ 391$, respectively. Lastly, a conception rate of $35 \%$ would lead to 839 heifer calves that cost an extra cost $\$ 118, \$ 286$, or $\$ 454$ apiece, respectively. Therefore, the purchase of sexed semen could be justified at $\$ 50$ per unit regardless of conception rate $(35,40$, or $45 \%)$, but a cost of $\$ 100$ per unit would be difficult to justify in this "conventional" scheme unless conception rates of $45 \%$ or greater could be achieved.

Extended age at first calving is also a major concern in breeding programs that utilize sexed semen for first and repeat services. As shown in Figure 1, only 38 (of 1000) heifers would calve later than 27 mo of age with unsexed semen, assuming a $70 \%$ heat detection rate and a minimum breeding age of 14 mo. When sexed semen is used for all inseminations; however, the number of heifers calving later than 27 mo of age increases to 103,139 , or 185 at conception rates of 45,40 , or $35 \%$, respectively. The opportunity cost of extending the age at first calving for a significant proportion of heifers would negate much of the benefit of sexed semen in this conventional strategy, even if cost of the semen were modest.

\section{BREEDING STRATEGIES THAT CAN BE IMPLEMENTED TODAY}

Amman (1999) suggested that the added benefit of sexed semen must be, at minimum, twice as large as

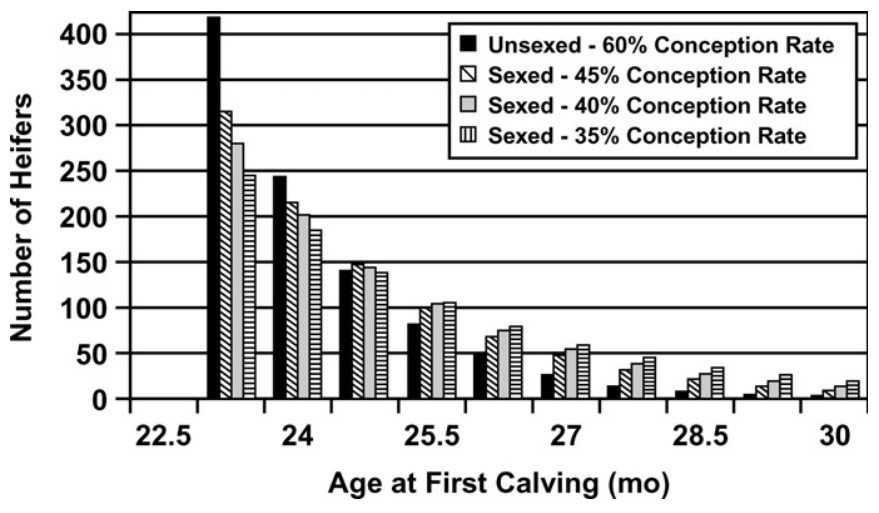

Figure 1. Expected distribution of age at first calving using sexed semen on every insemination (initial service and all repeat services) for 1000 dairy heifers, according to conception rate. Calculations assume a $70 \%$ heat detection rate. 
Table 5. Example of cost per heifer calf using sexed semen on an early first service only (the "early bird" scheme) for 1000 dairy heifers, according to conception rate and cost per unit of sexed semen. Calculations assume that unsexed semen costs $\$ 15$ per unit and that sexed semen results in $85 \%$ heifer calves.

\begin{tabular}{|c|c|c|c|c|c|c|c|c|c|}
\hline \multirow{2}{*}{$\begin{array}{l}\text { Semen } \\
\text { type }\end{array}$} & \multirow{2}{*}{$\begin{array}{l}\text { Conception } \\
\text { rate }\end{array}$} & \multicolumn{3}{|c|}{ No. Pregnant at service } & \multirow{2}{*}{$\begin{array}{l}\text { Units of } \\
\text { semen }\end{array}$} & \multirow{2}{*}{$\begin{array}{l}\text { Heifer } \\
\text { calves }\end{array}$} & \multicolumn{3}{|c|}{ Cost per heifer calf } \\
\hline & & 1 & 3 & 5 & & & $\$ 50$ Semen & $\$ 100$ Semen & $\$ 150$ Semen \\
\hline Unsexed & $60 \%$ & 600 & 936 & 990 & 1666 & 500 & $\$ 50$ & $\$ 50$ & $\$ 50$ \\
\hline Sexed & $45 \%$ & 450 & 912 & 986 & 1916 & 657 & $\$ 97$ & $\$ 173$ & $\$ 249$ \\
\hline Sexed & $40 \%$ & 400 & 904 & 985 & 2000 & 640 & $\$ 102$ & $\$ 180$ & $\$ 258$ \\
\hline Sexed & $35 \%$ & 350 & 896 & 983 & 1916 & 622 & $\$ 106$ & $\$ 187$ & $\$ 267$ \\
\hline
\end{tabular}

the added cost. In other words, if the cost of producing an extra heifer calf using sexed semen is $\$ 100$ (after accounting for higher semen price, lower conception rate, and extended age at first calving), then an extra female calf should be worth at least $\$ 200$ more than its male counterpart. Our discussion of in vivo applications of sexed semen, as well as in vitro applications that utilize dairy recipients, will focus on the expected cost per heifer calf, as compared with the cost of a heifer calf from unsexed AI semen. However, comparisons involving in vitro applications with beef recipients offer additional complications, because the relative value of female dairy calves is quite different from that of female beef calves, and because the option of double (twin) transfers exists. Therefore, these comparisons will be based on net calf value per recipient.

\section{The "Early Bird" Scheme}

The "early bird" scheme is very simple, as shown in Figure 2. Virgin heifers are bred once (and only once) with sexed semen, and this breeding occurs $3 \mathrm{wk}$ (one heat period) prior to implementation of the routine heifer breeding program. The underlying assumptions

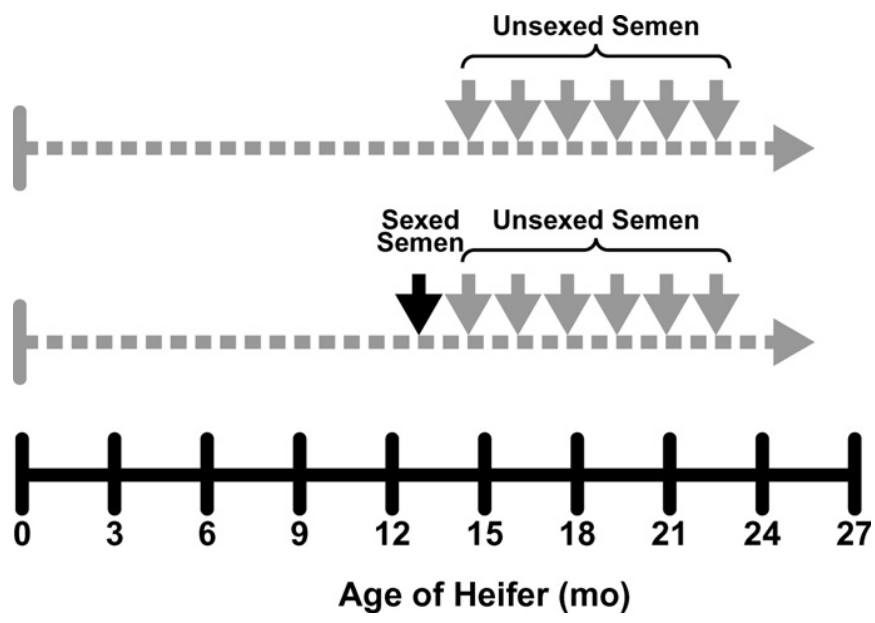

Figure 2. Schematic diagram of the "early bird" scheme. of this breeding scheme are as follows. First, conception rates with sexed semen are too low to justify the added semen cost (Table 4) and delay in age at first calving (Figure 1) that would occur if sexed semen were used at all services. Second, sexed semen will result in primarily heifer calves, and the corresponding reduction in calf size will offset (in terms of dystocia) any risks associated with calving $3 \mathrm{wk}$ younger. And third, because sexed semen will be targeted for virgin heifers, AI companies will offer sexed semen from only those bulls that are known to transmit outstanding service sire calving ease (i.e., small calves).

Table 5 shows the expected cost per heifer calf in the "early bird" scheme. The minimum breeding age is reduced to 13.25 months, and sexed semen is used for first services only. All repeat inseminations rely on unsexed semen. A herd size of 1000 heifers is assumed, with a conception rate of $60 \%$ for unsexed semen, a heat detection rate of $70 \%$, and a cost for unsexed semen of $\$ 15$ per unit. As shown in Table 5, the number of pregnant heifers after 5 services is quite comparable with that of unsexed semen, and the number of units of semen required decreases dramatically, as compared with the plan described earlier, in which all insemina-

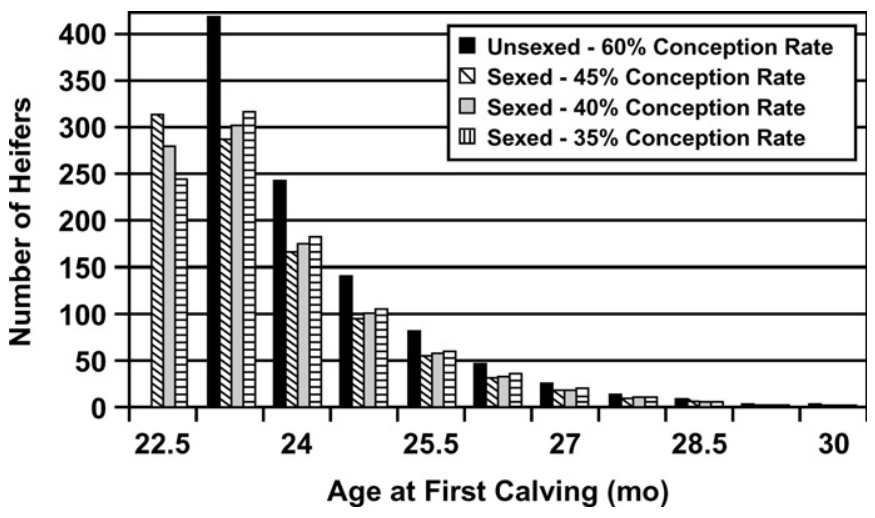

Figure 3. Expected distribution of age at first calving using sexed semen at an early first service only (i.e., the "early bird" scheme) for 1000 dairy heifers, according to conception rate. Calculations assume a $70 \%$ heat detection rate. 


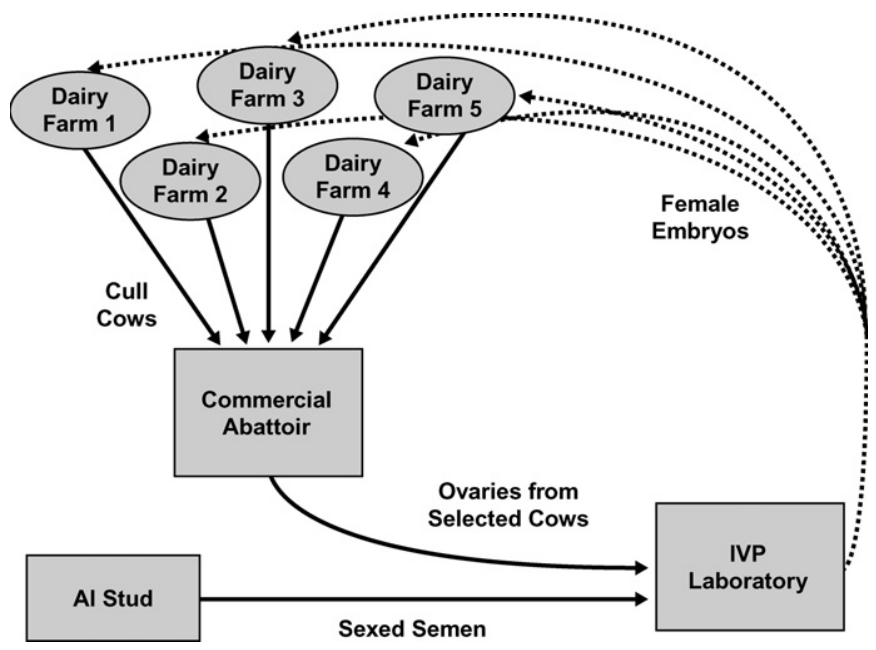

Figure 4. Schematic diagram of the "bovine recycling" scheme.

tions of heifers utilized sexed semen. The number of heifer calves produced by this scheme is 657,640 , or 622 , corresponding to conception rates of 45,40 , or $35 \%$, respectively. At a conception rate of $45 \%$, the additional cost per heifer calf (relative to controls) is $\$ 47, \$ 123$, or $\$ 199$ for sexed semen costing $\$ 50, \$ 100$, or $\$ 150$ per unit, respectively. Similarly, the additional cost per heifer calf is $\$ 52, \$ 130$, or $\$ 253$, respectively, for a conception rate of $40 \%$. Meanwhile, a conception rate of $35 \%$ would lead to an extra cost per heifer calf of $\$ 56$, $\$ 137$, or $\$ 217$, respectively. Thus, sexed semen could be justified at $\$ 50$ or $\$ 100$ per unit in the "early bird" scheme, but a cost of $\$ 150$ per unit could be justified only if the market price for heifer calves were extremely high. When sexed semen is used for an "early" first service, followed by resumption of the normal breeding program, the number of heifers with extended age at calving is slightly less than one achieves with unsexed semen only. As shown in Figure 3, unsexed semen leads to 38 (of 1000) heifers calving later than 27 mo of age, while sexed semen at an early first insemination, followed by unsexed semen for all repeat services, decreases this number to 29,27 , or 26 at conception rate of 45,40 , or $35 \%$, respectively. Therefore, it appears that an "early bird" scheme, in which sexed semen is used for an early first service only, can provide positive economic returns by producing extra replacement heifers at an affordable price with no corresponding increases in age at first calving.

\section{The "Bovine Recycling" Scheme}

The "bovine recycling" scheme combines IVP and sexed semen, as shown in Figure 4. Ovaries are retrieved at the time of slaughter from the best cows (genetically speaking) among all cows culled from a group of commercial dairies each month. If desired, the identity of the cow and her mate can be retained throughout the IVP and transfer process, such that the calves can be registered in a breed association herdbook. The underlying assumptions of this strategy are twofold. First, most dairy cows are culled for involuntary reasons (e.g., illness, injury, infertility, mastitis), and many of these "involuntary culls" are genetically suitable as dams of the next generation of replacement heifers. Second, the heritability values for most health and fertility traits are extremely low, so cows that are culled for these reasons are not necessarily genetically inferior for health or fertility (they may be subject to poor management or simply unlucky), and sire selection for health and fertility traits will offset any corresponding genetic inferiority among the donor dams.

An optimal IVP program that uses selected cull cows as donors will have a few key characteristics. Several large dairies must exist within reasonably close geographical proximity to each other, as well as to an abattoir and an IVP laboratory. Schedules for shipping animals to slaughter must be synchronized across herds, such that a large number of donors can be processed at one time. Managers of these dairies must agree to share the responsibility of providing donors and recipients, as well as the overall semen costs, laboratory fees, and transfer technicians. In this manner, variation in embryo production will "average out" across a large number of donors, and the total number of fresh, transferable embryos will closely match number of available recipients. Each farm may request "first right" to embryos from its own donors, but extra embryos must be transferred into any additional recipients that are available, because discarding IVP embryos is costly, as is leaving recipient animals open.

Table 6 shows the expected cost per heifer calf in an example "bovine recycling" scheme. Calculations assumed 10 cooperating 500 -cow dairies with a $30 \%$ annual cull rate; $20 \%$ of the cull cows are assumed to be suitable dams of the next generation of replacement heifers. It was assumed that 3.8 transferable embryos could be produced per donor, in agreement with Wilson et al. (2003). Sexed semen was assumed to produce 85\% female calves, and unsexed semen was assigned a price of $\$ 15$ per unit. Conception rates were $35 \%$ for $\mathrm{AI}$ inseminations, and 25, 20, or $15 \%$ for IVP transfers in milking cows. Corresponding conception rates in virgin heifers were $60,45,40$, or $35 \%$, respectively. The cost of producing female embryos (including laboratory fees, semen costs, and technician labor) was assumed to be either $\$ 50$ or $\$ 100$ per embryo.

As shown in Table 6, approximately 1140 transferable embryos could be produced annually, and transfers 
Table 6. Example of cost per heifer calf using sexed semen and in vitro embryo production (IVP) with known donors (the "bovine recycling" scheme) on 10 cooperating farms of 500 cows each, according to conception rate and cost per unit of sexed semen. Calculations assume a $30 \%$ annual cull rate, $20 \%$ of cull cows selected as donors, 3.8 transferable embryos per donor cow, $85 \%$ heifer calves from sexed semen, and $\$ 15$ per unit for unsexed semen.

\begin{tabular}{|c|c|c|c|c|c|c|c|c|c|}
\hline \multirow[b]{2}{*}{$\begin{array}{l}\text { Breeding } \\
\text { type }\end{array}$} & \multirow[b]{2}{*}{$\begin{array}{l}\text { Recipient } \\
\text { type }\end{array}$} & \multirow[b]{2}{*}{$\begin{array}{l}\text { Conception } \\
\text { rate }\end{array}$} & \multirow[b]{2}{*}{$\begin{array}{l}\text { No. } \\
\text { culls }\end{array}$} & \multirow[b]{2}{*}{$\begin{array}{l}\text { No. } \\
\text { donors }\end{array}$} & \multirow[b]{2}{*}{$\begin{array}{l}\text { No. } \\
\text { embryos }\end{array}$} & \multirow[b]{2}{*}{$\begin{array}{l}\text { No. } \\
\text { pregnancies }\end{array}$} & \multirow[b]{2}{*}{$\begin{array}{l}\text { No. heifer } \\
\text { calves }\end{array}$} & \multicolumn{2}{|c|}{ Cost per heifer calf } \\
\hline & & & & & & & & $\begin{array}{l}\$ 50 \text { per } \\
\text { embryo }\end{array}$ & $\begin{array}{l}\$ 100 \text { per } \\
\text { embryo }\end{array}$ \\
\hline IVP Embryo & Cows & $25 \%$ & 1500 & 300 & 1140 & 285 & 228 & $\$ 250$ & $\$ 500$ \\
\hline IVP Embryo & Cows & $20 \%$ & 1500 & 300 & 1140 & 228 & 194 & $\$ 294$ & $\$ 588$ \\
\hline IVP Embryo & Cows & $15 \%$ & 1500 & 300 & 1140 & 171 & 145 & $\$ 393$ & $\$ 786$ \\
\hline Unsexed AI & Heifers & $60 \%$ & & & & 684 & 342 & $\$ 50$ & $\$ 50$ \\
\hline IVP Embryo & Heifers & $35 \%$ & 1500 & 300 & 1140 & 399 & 339 & $\$ 168$ & $\$ 336$ \\
\hline
\end{tabular}

into virgin heifers would produce 94 or 46 extra heifer calves at conception rates of 45 or $40 \%$, respectively. However, only 28 additional heifer calves would be produced in milking cows, even if the conception rate for IVP transfers were 25\%. The added cost of producing a heifer calf by transferring female IVP embryos into milking cows, relative to the semen cost of $\$ 86$ for an AI heifer calf, ranged from $\$ 164$ to $\$ 700$, so it is clear that IVP programs utilizing cows as recipients will be profitable only if conception rates are high (e.g., $\geq 25 \%$ ) and embryo production costs are low (e.g., $\leq \$ 50$ ). On the other hand, the added cost per female calf using virgin heifers as recipients, as compared with the semen cost of $\$ 50$ for an AI heifer calf, ranged from only $\$ 81$ to $\$ 118$ for embryos costing $\$ 50$ each. However, the corresponding added cost ranged from $\$ 212$ to $\$ 286$ for embryos costing $\$ 100$ each. Therefore, it appears that a "bovine recycling" program with known IVP donors and sexed semen can be profitable if embryos can be produced at a cost approaching $\$ 50$ each and if conception rates of $40 \%$ or higher can be achieved. However, the risk of dystocia with IVP transfers into virgin dairy heifers must be considered, because the loss (death) of a few recipient heifers would negate most of the gains achieved by an altered sex ratio.

\section{The "Anonymous Donor" Scheme}

As shown in Figure 5, the "anonymous donor" scheme once again exploits the synergies of sexed semen and IVP, but it also takes advantage of higher conception rates in beef recipients, as well as lower embryo production costs using ovaries from unknown donors that are obtained "in bulk" from a commercial abattoir. The key assumptions of this breeding program are as follows. First, an individual beef cow produces more than one (i.e., her own) replacement during her lifetime, such that extra gestation periods can be "borrowed" for transfers of dairy embryos. Second, female dairy calves have significantly greater value than female beef calves. Third, calving problems occur less frequently in beef cows and heifers, as compared with dairy (i.e., Holstein) heifers. Fourth, the seasonal nature of beef production leads to the availability of a large number of (synchronized) recipients for fresh IVP embryos on a given day. Fifth, conception rates in beef cows are quite high, so inserting one or two "rounds" of IVP transfers at the beginning of the breeding season will not substantially alter the seasonal calving pattern of a beef operation. And sixth, the genetic merit of dairy cows that are sent to commercial abattoirs in the Untied States is reasonably good, on average, such that intense selection among sires will offset any genetic mediocrity that might be encountered among dams.

An example of the expected net calf value per recipient in the "anonymous donor" program is shown in Table 7. It was assumed that a 500-cow beef herd would purchase IVP embryos and transfer these at first and

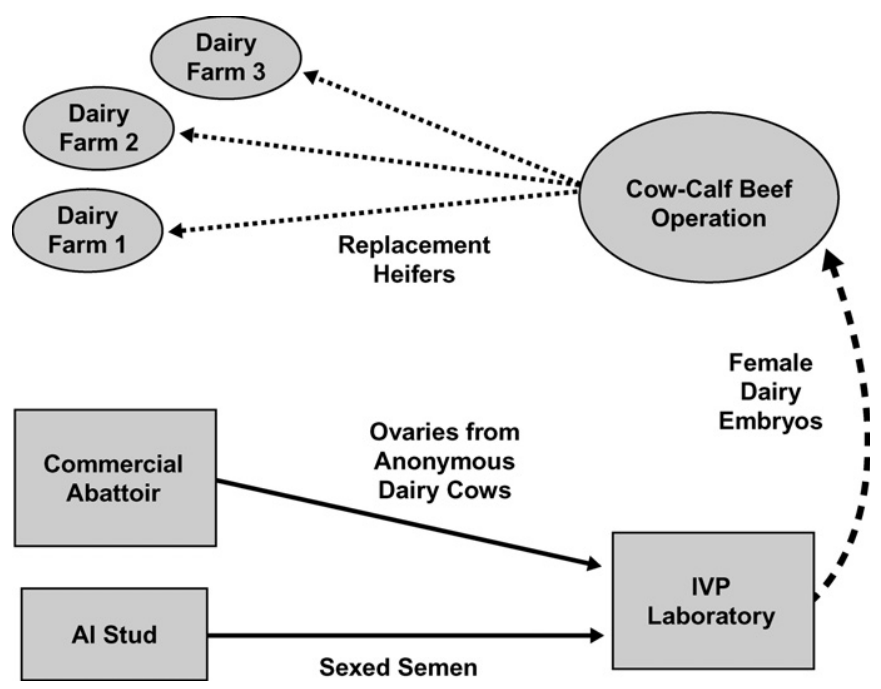

Figure 5. Schematic diagram of the "anonymous donor" scheme. 
Table 7. Example of net calf value per recipient using sexed semen and in vitro embryo production (IVP) with anonymous donors (the "anonymous donors" scheme) in a beef herd of 500 cows. Scheme involves 2 transfers per recipient, followed by resumption of the normal breeding program. Both heifers and cows are used as recipients. Calculations assume $\$ 15$ per unit for unsexed semen, $85 \%$ heifer calves from sexed semen, dairy heifer calf value of $\$ 400$, dairy bull calf value of $\$ 100$, beef heifer or bull calf value of $\$ 150,33 \%$ increase in overall conception rate with twin transfers, and 50\% twins among double transfer pregnancies.

\begin{tabular}{|c|c|c|c|c|c|c|c|c|c|}
\hline $\begin{array}{l}\text { Breeding } \\
\text { type }\end{array}$ & $\begin{array}{l}\text { Conception } \\
\text { rate }\end{array}$ & \multicolumn{2}{|c|}{ Round 1} & \multicolumn{2}{|c|}{ Round 2} & $\begin{array}{l}\text { Fertile } \\
\text { heifers }\end{array}$ & $\begin{array}{l}\text { Bulls and } \\
\text { freemartins }\end{array}$ & \multicolumn{2}{|c|}{ Net calf value/recipien } \\
\hline Single IVP embryo & $45 \%$ & 500 & 225 & 275 & 124 & 297 & 52 & $\$ 209$ & $\$ 171$ \\
\hline Single IVP embryo & $40 \%$ & 500 & 200 & 300 & 120 & 272 & 48 & $\$ 187$ & $\$ 147$ \\
\hline Single IVP embryo & $35 \%$ & 500 & 175 & 325 & 114 & 426 & 43 & $\$ 164$ & $\$ 123$ \\
\hline
\end{tabular}

(if necessary) second service for each cow and heifer. Calculations assumed a cost of $\$ 15$ per unit for unsexed AI semen, 85\% heifer calves from sexed semen, and calf values at birth of $\$ 400, \$ 100, \$ 150$, and $\$ 150$ for dairy heifer, dairy bull, beef heifer, and beef bull calves, respectively. It was further assumed that double transfers of IVP embryos would increase the overall conception rate by $33 \%$, and that $50 \%$ of calvings resulting from double transfers would be twins. Conception rates were assumed to be $65 \%$ for unsexed AI semen, and 45,40 , or $35 \%$ for IVP embryos (before accounting for double transfers).

As shown in Table 7, insemination with unsexed AI semen (at the first 2 services) would produce 220 beef heifer calves, while the transfer of single IVP embryos would produce 297,272 , or 246 dairy heifer calves at conception rates of 45,40 , or $35 \%$, respectively. On the other hand, transfer of double IVP embryos would produce 482,449 , or 411 fertile dairy heifer calves, respectively, after accounting for freemartins. Cost per fertile heifer calf (not shown) was slightly higher for double transfers than for single transfers, because the number of transfers increased twofold, while the conception rate increased only slightly. However, the key statistic in this production system is net calf value per recipient, and far more total heifer calves were produced via double transfers. As compared with a net calf value per recipient of $\$ 112$ for conventional $\mathrm{AI}$ with unsexed beef semen, single IVP transfers produced an extra $\$ 52$ to $\$ 97$ per recipient for embryos costing $\$ 25$ each and an extra $\$ 11$ to $\$ 59$ per recipient for embryos that cost $\$ 50$ each. Double IVP transfers generated an extra $\$ 171$ to $\$ 240$ per recipient for embryos costing $\$ 25$ each and an extra $\$ 95$ to $\$ 171$ per recipient for embryos that cost $\$ 50$ each. Therefore, it appears that an "anonymous donor" scheme with sexed semen and unknown ova donors provides an excellent opportunity for entrepre- neurial cow-calf operators to derive additional income by helping to satisfy the demand for dairy replacement heifers.

\section{CONCLUSIONS}

Technology for sexing bovine sperm is indeed on the verge of commercial application. However, 2 key limitations exist: sorting speed and conception rate. The breeding strategies discussed herein, including the "early bird" scheme, the "bovine recycling" scheme, and the "anonymous donor" scheme, are ready for implementation today, in spite of the aforementioned technical limitations. Each program offers the potential for widespread application within the routine management system of "mainstream" commercial dairy farms, because each can provide additional female dairy calves at a cost that represents less that half of their added value. In this manner, herds can satisfy their need for high quality replacement heifers, and biosecure herd expansions become possible. "Niche" applications also exist, such as the use of sexed semen in MOET nucleus herds, but these should not be the primary goal. In all cases, the protocol for sorting semen should be tailored to the final application of the product, just as the breeding program should be adjusted to accommodate the benefits and limitations of sexed semen. Synergies with other tools and technologies, such as IVP, crossbreeding, MOET, and heat synchronization, will be the key to successful commercial implementation of sexed semen.

\section{ACKNOWLEDGMENTS}

Financial support was generously provided by the University of Wisconsin Office for Corporate Relations and the Wisconsin Department of Agriculture, Trade, and Consumer Protection. Semen was generously provided by Accelerated Genetics and XY, Inc., while 
BOMED, Inc. provided in vitro production of embryos. Technical assistance was provided by Roy Wilson, Val Schutzkus, and Lee Matthews.

\section{REFERENCES}

Amann, R. P. 1999. Issues affecting commercialization of sexed sperm. Theriogenology 52:1441-1457.

Baker, R. L., P. Shannon, D. J. Garrick, H. T. Blair, and B. W. Wickham. 1990. The future impact of new opportunities in reproductive physiology and molecular biology on genetic improvement programmes. Proc. N.Z. Soc. Anim. Prod. 50:197-210.

Blecher, S. R., R. Howie, S. Li, J. Detmar, and L. M. Blahut. 1999. A new approach to immunological sexing of sperm. Theriogenology 52:1309-1321.

Bradley, M. P. 1989. Immunological sexing of mammalian semen: current status and future options. J. Dairy Sci. 72:3372-3380.

Hohenboken, W. D. 1999. Applications of sexed semen in cattle production. Theriogenology 52:1421-1433.

Johnson, L. A. 2000. Sexing mammalian sperm for the production of offspring: The state-of-the-art. Anim. Reprod. Sci. 60-61:93-107.

Johnson, L. A., J. P. Flook, and H. W. Hawk. 1989. Sex preselection in rabbits: Live births from $\mathrm{X}$ and $\mathrm{Y}$ sperm separated by DNA and cell sorting. Biol. Reprod. 41:199-203.

Johnson, L. A., J. P. Flook, and M. V. Look. 1987a. Flow cytometry of $\mathrm{X}$ and $\mathrm{Y}$ chromosome-bearing sperm for DNA using an improved preparation method and staining with Hoechst 33342. Gamete Res. 17:203-212.
Johnson, L. A., J. P. Flook, M. V. Look, and D. Pinkel. 1987b. Flow sorting of $\mathrm{X}$ and $\mathrm{Y}$ chromosome-bearing spermatozoa into two populations. Gamete Res. 16:1-9.

Johnson, L. A., G. R. Welch, and W. Rens. 1999. The Beltsville Sperm Sexing Technology: High-speed sorting gives improved sperm output for in vitro fertilization and AI. J. Anim. Sci. 77:213-220.

Lu, K. H., D. G. Cran, and G. E. Seidel, Jr. 1999. In vitro fertilization with flow-cytometrically-sorted bovine sperm. Theriogenology 52:1393-1405.

Montaldo, H., J. F. Keown, and L. D. Van Vleck. 1998. Effect of in vitro embryo production and sexed semen in dairy MOET nucleus systems. Proc. 6th World Congr. Genet. Appl. Livest. Prod. 25:443-446.

Seidel, G. E., Jr., and J. L. Schenk. 2002. Field trials with sexed, frozen bovine semen. Pages 64-69 in Proc. 19th Tech. Conf. on Artificial Insemination and Reproduction, Natl. Assn. of Animal Breeders, Columbia, MO.

Seidel, G. E., Jr., J. L. Schenk, L. A. Herickhoff, S. P. Doyle, Z. Brink, R. D. Green, and D. G. Cran. 1999. Insemination of heifers with sexed sperm. Theriogenology 52:1407-1420.

Wilson, R. D., K. A. Weigel, P. M. Fricke, and M. L. Leibfried-Rutledge. 2003. Combining in vitro embryo production and sexed semen technologies. J. Dairy Sci. 86(Suppl. 1):118. (Abstr.)

Van Vleck, L. D. 1981. Potential genetic impact of artificial insemination, sex selection, embryo transfer, cloning, and selfing in dairy cattle. Pages 222-242 in New Technologies in Animal Breeding. B. G. Brackett, G. E. Seidel, and G. E. Seidel, eds. Academic Press, New York, NY.

Van Vleck, L. D., and R. W. Everett. 1976. Genetic value of sexed semen to produce dairy heifers. J. Dairy Sci. 59:1802-1807.

Young, C. W. 1988. Implementing technology for genetic improvement: Sire-daughter and dam-daughter paths, farm management's view. J. Dairy Sci. 71:1982-1992. 